\title{
Flexural Capacity of Locally Buckled Steel I-Beams Under Moment Gradient
}

\author{
Amin Mohebkhah ${ }^{1, *}$ and Behrouz Chegeni ${ }^{2}$
}

${ }^{I}$ Structural Engineering Division, Faculty of Civil and Architectural Engineering, University of Malayer, Malayer, Iran; ${ }^{2}$ Young Researchers and Elite Club, Khorramabad Branch, Islamic Azad University, Khorramabad, Iran

\begin{abstract}
Lateral-torsional buckling (LTB) and flange local buckling (FLB) are treated as two independent phenomena in AISC-LRFD 360-10 in which the flexural capacity of locally buckled beams is determined as the minimum value obtained for the limit states of LTB and FLB. A 3-D nonlinear finite-element model using ABAQUS is developed in this research to investigate the interactive flexural capacity of steel I-beams with compact web under moment gradient. It was found that the AISC approach is adequate for beams with compact or noncompact sections, however, too conservative for beams with slender flanges representing a considerable interaction between LTB and FLB limit states.
\end{abstract}

Keywords: Lateral-torsional buckling, flange local buckling, finite element method, interactive buckling, moment gradient, Ibeam.

\section{INTRODUCTION}

Lateral-torsional buckling (LTB) is a global buckling mode in which the in-plane deflection of a laterally unbraced beam changes to a mixed lateral deflection and twisting. According to the AISC-LRFD 360 [1], the nominal elastic LTB moment capacity of I-beams under moment gradient (nonuniform bending) is given by:

$$
M_{n(L T B)}=F_{c r} S_{x}
$$

where

$$
\begin{aligned}
& F_{c r}=\frac{C_{b} \pi^{2} E}{\left(L_{b} / r_{t s}\right)^{2}} \sqrt{1+0.078 \frac{J c}{S_{x} h_{0}}\left(L_{b} / r_{t s}\right)^{2}} \\
& r_{t s}{ }^{2}=\frac{\sqrt{I_{y} C_{w}}}{S_{x}}
\end{aligned}
$$

and $\mathrm{C}_{\mathrm{b}}$ is the equivalent uniform moment factor that accounts for the effect of moment gradient on the nominal critical moment capacity. The equivalent uniform moment factor for a concentrated loading at shear center is 1.35 as given in AISC-LRFD 360 [1].

For a beam that buckles inelastically, AISC-LRFD 360 [1] gives a linear transition equation from the end of the elastic region to the beginning of the plastic region. The basic assumption of the transition equation is that the beam crosssection is a compact section which can reach its plastic moment capacity $\left(\mathrm{M}_{\mathrm{p}}\right)$ for $\mathrm{L}_{\mathrm{b}} \leq \mathrm{L}_{\mathrm{p}}$ with no local buckling. For compact sections, the plastic moment resistance takes place prior to the occurrence of local buckling in their constituent plates. However, for noncompact and slender I-beam

*Address correspondence to this author at the Structural Engineering Division, Faculty of Civil and Architectural Engineering, University of Malayer, Malayer, Iran; Tel: +98 08512232346 ; Fax: +98 08512221977 ;

E-mail: amoheb@malayeru.ac.ir sections (having either flanges or web with high slenderness), flange local buckling (FLB) or web local buckling (WLB) takes place prior to the attainment of their in-plane plastic moment capacity.

The nominal moment resistance for I-beam sections with noncompact or slender flanges is estimated as the minimum value of the independently estimated LTB and FLB moment capacities as per the Specification AISC-LRFD 360 [1]. In other words, the interaction between FLB and LTB is neglected in the AISC-360 provisions for all ranges of local and global buckling slendernesses. The elastic moment capacity of laterally supported sections with slender flanges is determined as follows (AISC-LRFD 360 [1]):

$$
M_{n(F L B)}=\frac{0.9 E k_{c} S_{x}}{\lambda_{f}^{2}}
$$

In which $\lambda_{f}, \mathrm{~S}_{\mathrm{x}}$ are the compression flange local slenderness and the elastic section modulus, respectively, and parameter $\mathrm{k}_{\mathrm{c}}$ is computed as $4 / \sqrt{h / t_{w}}$.

Similar to the approach adopted for inelastic LTB capacity prediction, AISC-LRFD 360 [1] gives a linear transition equation between plastic moment and reduced yield moment due to the presence of residual stresses (i.e. $M_{r}=S_{x}\left(F_{y}-F_{r}\right)$ $=0.7 M_{y}$ ) to estimate the moment capacity of laterally supported sections with noncompact flanges as follows:

$$
M_{n(F L B)}=M_{p}-\left(M_{p}-0.7 M_{y}\right)\left(\frac{\lambda_{f}-\lambda_{p f}}{\lambda_{r f}-\lambda_{p f}}\right)
$$

There are few laboratory tests [2-4] and numerical studies on the lateral-torsional buckling of steel beams with locally buckled compression flanges. Wang et al. [5] investigated the lateral-torsional buckling of locally buckled Ibeams using a FEA and the Winter's effective width con- 
cept. They found that locally buckled beams have a considerable post-local-buckling resistance; however, this may not be fully attained due to the occurrence of global LTB in the post-local-buckling range for beams with intermediate beams [5]. Bradford and Hancock [6] developed a nonlinear finite strip method (FSM) as an alternative to the Winter effective width [7] formula of a locally buckled beam to determine the strength of the beam to LTB phenomenon. They found that there is no significant interaction between local and global buckling modes for sections with thick flanges and thin webs, even though the Winter effective width calculation shows that there will be an interaction [6]. Bradford [8] studied the local buckling behavior of I-section beam-columns using a FSM and obtained the graphs of the FLB coefficient considering interactive flange-web buckling modes. White and Kim [9] state that assuming the FLB coefficient of $\mathrm{k}_{\mathrm{c}}=0.76$ in the AISC-LRFD formula (i.e. Eq. 4) is sufficient to consider the LTB and FLB as two separate phenomena with no interaction. Although LTB and FLB phenomena are treated separately in AISC-LRFD 360 [1] with no interaction, however, Mohebkhah and Chegeni [10] showed that for beams with slender flanges under pure bending, as the ratio $\mathrm{M}_{\mathrm{n}(\mathrm{LTB})} / \mathrm{M}_{\mathrm{n}(\mathrm{FLB})}$ becomes more than one, there would be an interaction between FLB and LTB limit states and the AISCLRFD buckling moment prediction is too conservative. Kwon and Seo [4] conducted some experiments on welded $\mathrm{H}$-section beams undergoing local buckling and lateraltorsional buckling simultaneously. They concluded that local buckling prior to the LTB, has a significant post-localbuckling strength reserve, however, reduces flexural moment capacity to some extent. Furthermore, Kwon and Seo [4] proposed a simple flexural strength formula for the direct strength method (DSM) design of welded sections under pure bending to account for the interaction between local and lateral-torsional buckling as follows:

$$
\frac{M_{n}}{M_{n(L T B)}}=\left\{\begin{array}{lll}
1 & \text { for } & \lambda \leq 0.816 \\
\frac{\lambda-0.15}{\lambda^{2}} & \text { for } & \lambda \succ 0.816
\end{array}\right.
$$

in which the slenderness parameter $\lambda$ is defined as $\left(M_{n(L T B)} M_{n(F L B)}\right)^{0.5}$.

Although there are many studies in the literature on local buckling of I-beams, the effect of FLB on the LTB resistance of I-beams with different unbraced lengths and flange slendernesses has not been studied under moment gradient. In this paper, the effects of unbraced length and FLB phenomenon on the global LTB moment resistance of steel I-beams are investigated under a central concentrated loading at shear center. To achieve this end, a 3-d FEM model based on software ABAQUS [11] is developed for the nonlinear buckling analysis of I-beams with a wide variety of local and global slendernesses. Then, the model is utilized to study the applicability of the AISC-LRFD method and DSM formula proposed by Kwon and Seo [4] in determining the moment capacity of locally buckled built-up steel I-beams with various flange slendernesses (having compact webs) and unbraced span-lengths.

\section{MATERIALS AND METHODOLOGY}

In this section a nonlinear finite element model is developed to simulate the inelastic LTB behavior of built-up I- beams under moment gradient. The assumptions and specifications of the adopted modeling technique are described in the following subsections.

\subsection{Modeling Assumptions and Material Properties}

The built-up I-beams were modeled using the finite element software ABAQUS [11]. Two types of nonlinearities (i.e. material and geometric) are taken into account in ABAQUS [11] for the nonlinear finite element analysis of a given model. To include large displacement effects in the models, the nonlinear geometry option in ABAQUS [11] was utilized. For the numerical models the ABAQUS S4R element were used to represent the web, flanges and the end supports stiffeners. ABAQUS S4R element is a robust, general-purpose element that is suitable for a wide range of applications such as explicit simulation of buckling deformations and plasticity effects. The S4R element is a four-node element with six DOFs per node, 3 translational and 3 rotational.

Depending on the models' flange width and web height, the flanges were divided into four to eight elements across the width and 6 to 9 elements were used to model the web. The same material properties were used for the flanges and web of the models. To include the material nonlinearity effect, the ABAQUS metal plasticity model with kinematic hardening was utilized. This model uses the von Mises yield criterion and associated plastic flow theory. An elasticperfect plastic model based on a simplified bilinear stressstrain curve

without strain hardening was assumed in the finiteelement model. The nominal yield stress, modulus of Elasticity and Poisson's ratio of $235 \mathrm{MPa}, 200000 \mathrm{MPa}$ and 0.3 were adopted, respectively. Residual stresses were not considered in this study.

\subsection{Loads, Boundary Conditions and Solution Procedure}

Simply supported built-up I-beams with different unbraced lengths and flange slendernesses are chosen under $a$ central concentrated loading at shear center (nonuniform bending) in order to determine their moment capacities. According to the AISC-LRFD 360 [1], compact and noncompact limits for flexural members' flange are taken as $0.38\left(E / F_{y}\right)^{1 / 2}$ and $0.95\left(k_{c} E / 0.7 F_{y}\right)^{1 / 2}$, respectively.

The nonlinear analysis solution was achieved using the Newton-Rhapson method in conjunction with the modified RIKS method and the large displacement theory. Geometric imperfections are also accounted for the analysis. To take into account geometric imperfections in the analysis, an Eigenvalue analysis is also utilized to obtain the mode shapes of the models under the applied loads. To have a suitable amplitude for the geometric imperfections, a scaling factor of $\mathrm{L}_{\mathrm{b}} / 1000$ was adopted. Then, the scaled buckled mode shape was added as an initial imperfection patter to the original geometry throughout the beam length.

\section{FINITE ELEMENT MODEL VALIDATION}

The validity of the modeling technique is verified in this part by numerical modeling of specimens tested by Kwon 
and Seo [4]. Kwon and Seo [4] performed some flexural tests on a series of welded $\mathrm{H}$-sections fabricated from steel plates of thickness $6.0 \mathrm{~mm}$. In the test program, two concentrated (knife-edge) loads were applied at approximately onethird points of top flange in vertical direction as shown in (Fig. 1). The full geometry of the setup including flanges, webs and stiffeners was modeled.

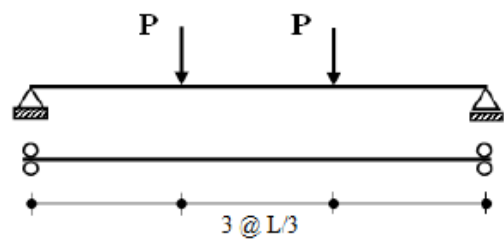

Fig. (1). Loading scheme of slender specimens tested by Kwon and Seo [4].

Among the tested specimens, specimens H350-600, H400-600 and H400-400 were modeled and analyzed using the developed FEM model in Sec. 2. The yield stress of the material was taken as 413.0MPa. Young's modulus and Poisson's ratio of $200 \mathrm{GPa}$ and 0.3 were assumed. The critical buckling moment capacities of the specimens obtained from the experiments and the FE analysis are compared in (Table 1). As it is seen, there is a satisfactory accordance between the test buckling moments and the moments determined using the FEM. Numerically obtained failure mode of specimen H350-600 has been shown in (Fig. 2) which is in good agreement with the failure mode observed in the test.

\section{PARAMETRIC STUDY}

In this section using the validated FE model, a nonlinear buckling analysis is conducted to investigate the effects of FLB phenomenon on the LTB moment resistance of built-up
I-beams under nonuniform bending (concentrated loading at midspan). To this end, a wide range of flange slendernesses was selected to investigate the abovementioed aim for both elastic and inelastic beams. All of the sections are considered to have compact webs. Therefore, the web height and thickness were kept equal to $300 \mathrm{~mm}$ and $10 \mathrm{~mm}$ respectively for all sections (i.e. compact webs) except just for one section. To perform a parametric study, 10 cross sections with different flange slendernesses were considered as shown in (Table 2). For convenience, these models were assigned a specific symbol as Sm- $n$ where $m$ and $n$ stand for the flange total width and thickness in $\mathrm{mm}$, respectively. The web height and thickness of model S400-6 are equal to $400 \mathrm{~mm}$ and $10 \mathrm{~mm}$, respectively.

In order to investigate the global LTB of locally buckled sections in different behavioral regions, the cross sections were analyzed with different span lengths (46 models). The interactive buckling moment resistances of the FEM models $(\mathrm{Mn}(\mathrm{FEM}))$ are given in (Table 2) along with the buckling moments determined by the AISC-LRFD provisions. As it was pointed out earlier, the AISC-LRFD moment resistance $\left(\mathrm{M}_{\mathrm{n}(\mathrm{AISC})}\right)$ is estimated as the minimum of the LTB and FLB moment capacities In fact, the LTB and FLB limit states are treated as two independent phenomena. The original AISLRFD flange local buckling and lateral-torsional buckling moment capacities have been derived taking into account the effects of residual stresses. However, bacause of considering no residual stresses in the above finite element analyses; the AISC-LRFD FLB and LTB resistance formulas were computed with zero residual stresses to be compared with the corresponding FEM results. Furthermore, the dimensionless moment capacities of the cross sections calculated based on the DSM design formula proposed by Kwon and Seo [4] are given in (Table 2) to be compared with the FEM and AISC results.

Table 1. Comparison of Slender Beam Tests Results from Kwon and Seo [4] to the FEM Results

\begin{tabular}{|c|c|c|c|c|c|c|}
\hline Specimen & $\mathbf{L}(\mathbf{m m})$ & $\mathbf{t}(\mathbf{m m})$ & $\mathbf{M}_{\text {TEST }}(\mathbf{k N m})$ & $\mathbf{M}_{\text {FEM }}(\mathbf{k N m})$ & Failure Mode & Difference \% \\
\hline \hline H350-600 & 10000 & 6 & 483.9 & 485.03 & FLB & 0.2 \\
\hline H400-600 & 10000 & 6 & 494.2 & 483.14 & FLB & 2.2 \\
\hline H400-400 & 10000 & 6 & 328.3 & 335.7 & FLB & 2.2 \\
\hline
\end{tabular}

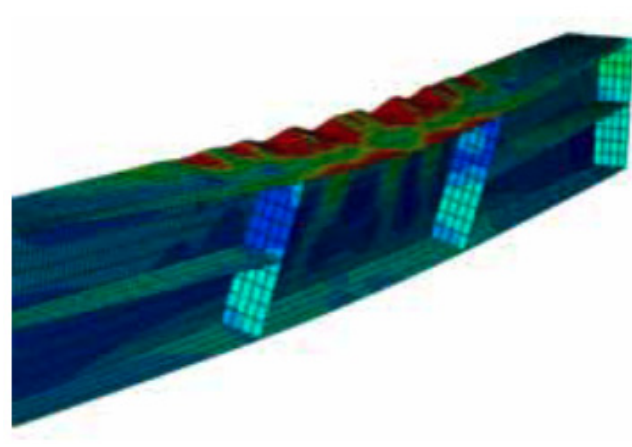

(a)

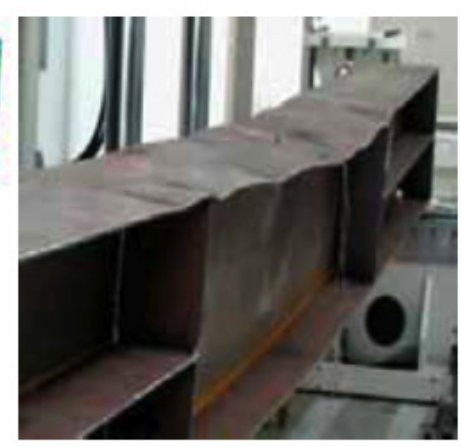

(b)

Fig. (2). Deformed shape of specimen H350-600 by: (a) FEM and (b) test (Kwon and Seo 2012). 
Table 2. The AISC-LRFD and FEM Moment Capacities of the Studied Sections Under Nonuniform Bending

\begin{tabular}{|c|c|c|c|c|c|c|c|c|c|c|}
\hline \multirow[b]{2}{*}{ Section } & \multirow{2}{*}{$\begin{array}{l}\text { Section } \\
\text { class }\end{array}$} & \multirow{2}{*}{$\begin{array}{c}\mathrm{M}_{\mathrm{p}} \\
(\mathrm{kN}-\mathrm{m})\end{array}$} & \multirow{2}{*}{$\begin{array}{l}\mathbf{L}_{\mathrm{b}} \\
(\mathbf{m})\end{array}$} & \multicolumn{3}{|c|}{ AISC-LRFD } & \multirow{2}{*}{$\begin{array}{l}\mathbf{M}_{\mathrm{n}(\mathrm{FEM})} \\
(\mathrm{kN}-\mathrm{m})\end{array}$} & \multirow{2}{*}{$\frac{M_{n(A I S C)}}{M_{n(F E M)}}$} & \multirow{2}{*}{$\lambda$} & \multirow{2}{*}{$\frac{M_{n(\text { Kwon })}}{M_{n(\text { LTB })}}$} \\
\hline & & & & $\begin{array}{l}M_{n(F L B)} \\
(k N-m)\end{array}$ & $\begin{array}{l}M_{\mathrm{n}(\mathrm{LTB})} \\
(\mathrm{kN}-\mathrm{m})\end{array}$ & $\begin{array}{l}\mathbf{M}_{\mathrm{n}(\mathrm{AISC})} \\
(\mathrm{kN}-\mathrm{m})\end{array}$ & & & & \\
\hline \multirow{4}{*}{ S200-10 } & \multirow{4}{*}{ Comp. } & \multirow{4}{*}{198.6} & 3.10 & \multirow{4}{*}{198.6} & 260.3 & 198.6 & 192.5 & 1.03 & 1.14 & 0.76 \\
\hline & & & 3.97 & & 251.8 & 198.6 & 191.8 & 1.03 & 1.13 & 0.77 \\
\hline & & & 5.70 & & 235.2 & 198.6 & 183.7 & 1.08 & 1.1 & 0.79 \\
\hline & & & 6.57 & & 190.5 & 190.5 & 179.1 & 1.06 & 1.00 & 0.86 \\
\hline \multirow{2}{*}{ S200-8 } & \multirow{2}{*}{ Noncomp. } & \multirow{2}{*}{168.7} & 3.00 & \multirow{2}{*}{166.7} & 219.8 & 166.7 & 164.2 & 1.01 & 1.15 & 0.76 \\
\hline & & & 6.43 & & 152.5 & 152.5 & 147.4 & 1.03 & 0.96 & 0.88 \\
\hline \multirow{5}{*}{ S200-6 } & \multirow{5}{*}{ Noncomp. } & \multirow{5}{*}{139.2} & 2.86 & \multirow{5}{*}{130.7} & 180 & 130.7 & 136.5 & 0.96 & 1.17 & 0.74 \\
\hline & & & 3.67 & & 172.4 & 130.7 & 131.2 & 1.00 & 1.15 & 0.76 \\
\hline & & & 4.50 & & 164.6 & 130.7 & 127.8 & 1.02 & 1.12 & 0.77 \\
\hline & & & 5.35 & & 151.7 & 130.7 & 123.9 & 1.05 & 1.08 & 0.80 \\
\hline & & & 6.19 & & 121.4 & 121.4 & 117.6 & 1.03 & 0.96 & 0.88 \\
\hline S300-10 & Noncomp. & 271.4 & 4.92 & 263.9 & 357.5 & 263.9 & 268.2 & 0.98 & 1.16 & 0.75 \\
\hline \multirow{4}{*}{ S300-8 } & & & 6.06 & & 287.3 & 213 & 219.9 & 0.97 & 1.16 & 0.75 \\
\hline & Noncomp. & 226.6 & 7.34 & 213 & 277.7 & 213 & 214.3 & 1.00 & 1.14 & 0.76 \\
\hline & & & 8.63 & & 257.8 & 213 & 209.7 & 1.02 & 1.10 & 0.78 \\
\hline & & & 9.92 & & 207.5 & 207.5 & 207.2 & 1.00 & 0.99 & 0.86 \\
\hline & & & 4.56 & & 237.5 & 143.9 & 173.8 & 0.83 & 1.28 & 0.69 \\
\hline & & & 5.84 & & 228.3 & 143.9 & 173 & 0.83 & 1.26 & 0.70 \\
\hline S300-6 & Slender & 182.3 & 7.12 & 143.9 & 219 & 143.9 & 168.1 & 0.86 & 1.23 & 0.71 \\
\hline & & & 8.4 & & 198.9 & 143.9 & 167 & 0.86 & 1.17 & 0.74 \\
\hline & & & 9.7 & & 158.4 & 143.9 & 162.3 & 0.89 & 1.05 & 0.82 \\
\hline & & & 5.83 & & 406.2 & 294.6 & 303.8 & 0.97 & 1.17 & 0.74 \\
\hline & & & 7.34 & & 396.0 & 294.6 & 300.9 & 0.98 & 1.16 & 0.75 \\
\hline & & & 10.33 & & 371.8 & 294.6 & 295 & 1.0 & 1.12 & 0.77 \\
\hline & & & 11.83 & & 302.7 & 294.6 & 291.2 & 1.01 & 1.01 & 0.84 \\
\hline
\end{tabular}


(Table 2) contd....

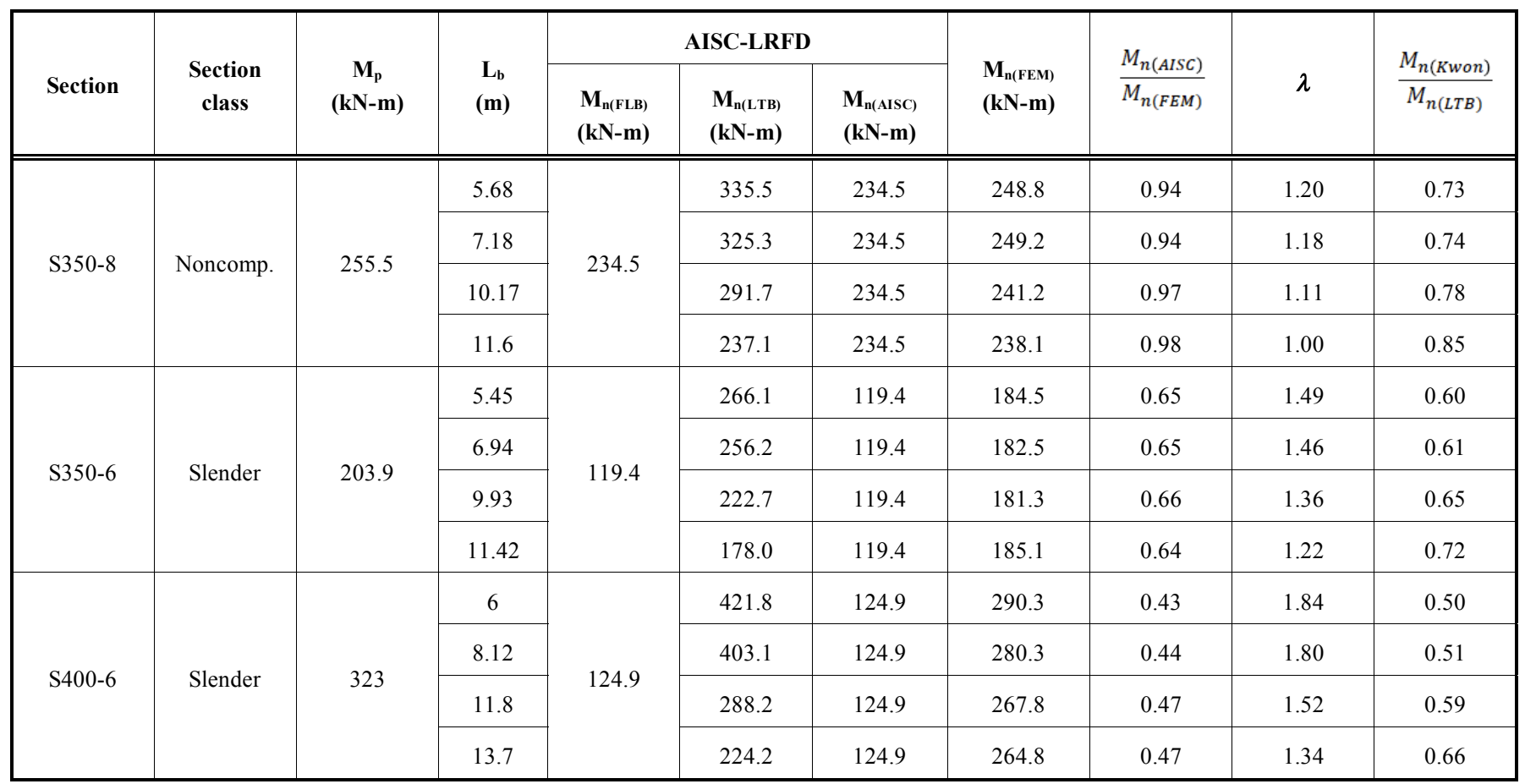

\section{DISCUSSION OF THE RESULTS}

As it is seen in Table 2 , for most of the cases with compact and noncompact sections, the moment capacities given by AISC-LRFD are approximately equal to the values predicted by the FEM. This indicates that the AISC approach to determine the moment capacity of locally buckled unbraced beams is adequate for design purposes and hence, the LTB and FLB limit states can be considered as two independent phenomena with no interaction for beams with compact or noncompact sections. The AISC-LRFD flange local buckling, lateral-torsional buckling and the FEM moment capacities for the noncompact section S200-6 with different spanlengths are shown in (Fig. 3). It is seen that the FEM moment capacity of the beam can be estimated by the simple AISC approach with a maximum error of $5 \%$.

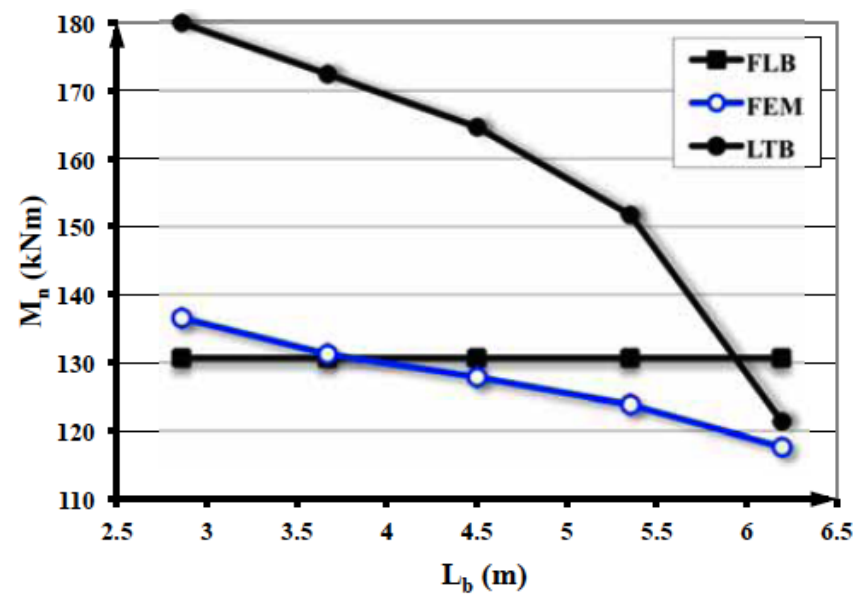

Fig. (3). The AISC-LRFD FLB, LTB and FEM moment capacities for the noncompact section S200-6.
The AISC-LRFD FLB, LTB and FEM moment capacity predictions for the slender section S350-6 are illustrated in (Fig. 4). In this case, contrary to the section S200-6, it can be seen that the AISC approach is too conservative for beams with slender flanges (underestimation up to $57 \%$ for section S400-6) due to ignoring the interaction between the FLB and LTB phenomena. Also, it can be seen that the FEM buckling moment capacity of the slender section does not depend on the unbraced length of the beams indicating the FLB mode as the governing failure mode. However, despite the identical governing failure modes predicted by both the FEM and AISC approaches, there is no agreement between their estimated moment capacities. The discrepancy between the FEM and AISC predictions for the slender sections can be due to the post-local-buckling reserve strength of compression flanges. This post-local-buckling resistance may be due to the redistribution of the flange bending compressive stresses over the flange effective width which has not been taken into account in the AISC FLB moment capacity formula (i.e. Eq. 5) derivation.

In order to compare the results of this study with the findings of the other researchers, the moment capacity of the sections was also estimated by the DSM design formula given by Kwon and Seo [4] as shown in Table 2. Variation of estimated moment capacities of the sections by the AISC, FEM and Kwon's approaches is illustrated against the dimensionless slenderness parameter $\lambda$ in (Fig. 5). It can be observed that as the ratio $\mathrm{Mn}(\mathrm{LTB}) / \mathrm{Mn}(\mathrm{FLB})$ becomes larger than unity (i.e. the distance between the global and local buckling capacities becomes larger, $\lambda>1.2$ ), the AISCLRFD buckling moment prediction is too conservative for slender beams with slender sections. However, the DSM design formula proposed by Kwon due to considering the FLB and LTB interaction presents an accurate estimation of locally buckled sections as a lower-bound to the FEM 


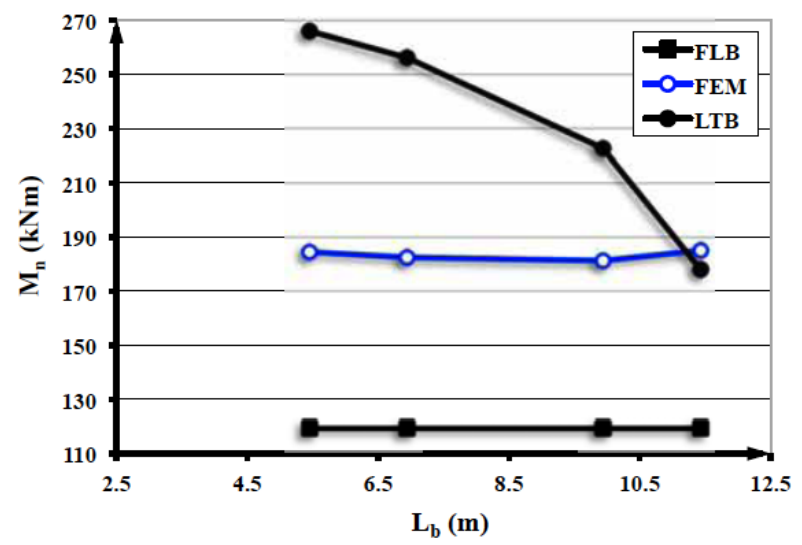

Fig. (4). The AISC-LRFD FLB, LTB and FEM moment capacities for the sections S350-6.

results. This shows the capability of Kwon's formula for flexural capacity of steel beams with slender sections under nonuniform bending.

\section{CONCLUSIONS}

This study deals with the inelastic LTB strength of different built-up steel beams (i.e. with compact, noncompact and slender sections) under moment gradient (i.e. concentrated load at shear center) using FEM. To this end, the interactive buckling resistance of elastic and inelastic steel Ibeams undergoing simultaneous LTB and FLB phenomena was taken into account. It was found that, the AISC-LRFD approach is applicable to steel beams with compact and noncompact sections indicating no interaction between the local and global buckling phenomena. However, the AISC approach is too conservative for beams with slender flanges due to ignoring the interaction between the FLB and LTB phenomena. The discrepancy between the FEM and AISC predictions for the slender sections is due to the post-localbuckling reserve strength of compression flanges which has not been considered in the AISC-LRFD flange local buckling moment capacity formula Furthermore, it was shown that the DSM design formula due to considering the FLB and LTB interaction and post-local-buckling of compression flanges, provides an accurate estimation of locally buckled sections' capacity under moment gradient as a lower-bound to the FEM. However, since the number of beams investigated in this study is limited, the results are not conclusive. Therefore, more numerical and experimental investigations should be conducted to prove the results.

\section{CONFLICT OF INTEREST}

The author(s) confirm that this article content has no conflicts of interest.

\section{ACKNOWLEDGEMENT}

Declared none.

\section{NOMENCLATURE}

$C_{w} \quad=\quad$ Warping section constant

$E \quad=$ Young's modulus of elasticity

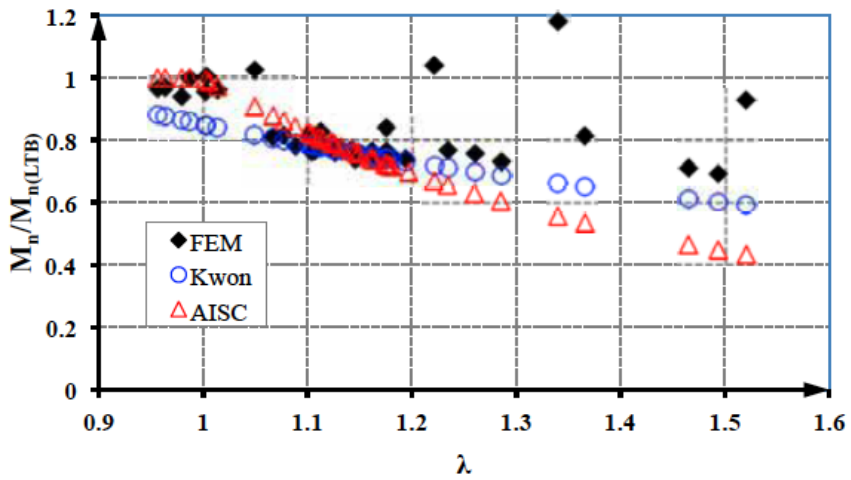

Fig. (5). Variations of the normalized moment capacity predictions for the studied beams.

$F_{r} \quad=\quad$ Residual stress of beams equal to $0.3 \mathrm{~F}_{\mathrm{y}}$

$F_{y} \quad=$ Yield stress of steel

$G \quad=\quad$ Shear modulus of elasticity

$I_{y} \quad=\quad$ Second moment of area about $\mathrm{y}$-axis

$J \quad=$ Torsional section constant

$L_{b} \quad=\quad$ Unbraced length of the beam

$L_{r} \quad=$ Limiting unbraced length to achieve the onset of yielding in pure bending

$L_{p} \quad=$ Limiting unbraced length to achieve the plastic moment in pure bending

$M_{p} \quad=\quad$ Section plastic moment capacity

$M_{n(F L B)}=$ Flange local buckling moment capacity

$M_{n(L T B)}=$ Lateral-torsional buckling moment capacity

$M_{n(A I S C)}=$ Minimum value of $\mathrm{M}_{\mathrm{n}(\mathrm{FLB})}$ and $\mathrm{M}_{\mathrm{n}(\mathrm{LTB})}$

$S_{x} \quad=$ Elastic section modulus

$Z \quad=$ Plastic section modulus

$\lambda_{f} \quad=$ Slenderness parameter for flange

$\lambda_{p f}=$ Limiting slenderness parameter for compact flange

$\lambda_{r f}=$ Limiting slenderness parameter for noncompact flange

\section{REFERENCES}

[1] AISC 360-10. Specification for structural steel buildings. American Institute of Steel Construction, Inc., Chicago, IL., 2010.

[2] S. Cherry, "The stability of beams with buckled compression flanges", The Structural Engineer, vol. 38, no. 9, pp. 277-285, 1960.

[3] J. F. Richter, "Flexural capacity of slender web plate girders", M.Sc. thesis, University of Texas, Austin, Texas, USA, 1998.

[4] Y. B. Kwon, and G. H. Seo, "Prediction of the flexural strengths of welded H-sections with local buckling", Thin-walled Structures, vol. 54, pp. 126-139, 2012.

[5] S. T. Wang, M. I. Yost, and Y. L. Tien, "Lateral buckling of locally buckled beams using finite element techniques", Computers and Structures, vol. 7, no. 7, pp. 469-475, 1977. 
[6] M. A. Bradford, and G. J. Hancock, "Elastic interaction of local and global buckling in beams", Thin-walled Structures, vol. 2, pp. $1-25,1984$.

[7] T. V. Galambos, Guide to Stability Design Criteria for Metal Structures, Structural Stability Research Council, $5^{\text {th }}$ ed, John Wiley \& Sons Inc., New York, N.Y., USA, 1998.

[8] M. A. Bradford, "Local buckling of semi-compact I-beams under biaxial bending and compression", Thin-walled Structures, vol. 19, pp. 33-48, 1991.
[9] D. W. White, and Y. D. Kim, "Unified flexural resistance equations for stability design of steel I-section members: moment gradient tests", Journal of Structural Engineering, ASCE, vol. 134, no. 9, pp. 1471-1786, 2008.

[10] A. Mohebkhah, and B. Chegeni, "Local-global interactive buckling of built-up I-beam sections", Thin-walled Structures, vol. 56, pp. 33-37, 2012.

[11] ABAQUS, Standard User's Manual, Hibbitt, Karlsson and Sorenson, Inc., 2008.

Received: November 03, 2013

Revised: December 18,2013

Accepted: December 18, 2013

(C) Mohebkhah and Chegeni; Licensee Bentham Open.

This is an open access article licensed under the terms of the Creative Commons Attribution Non-Commercial License (http://creativecommons.org/licenses/by-nc/3.0/) which permits unrestricted, non-commercial use, distribution and reproduction in any medium, provided the work is properly cited. 